of the proposed two-domain model for our thiols on Ag.

\section{Conclusions}

We have reported a multitechnique study of $n$-alkanethiolate monolayers at evaporated Ag surfaces. Optical ellipsometry yields thicknesses which are consistent with the formation of films one molecular layer thick. Contact angle measurements of long-chain $(n \geq 12)$ monolayers indicate densely packed and well-ordered films. Infrared spectroscopy shows the long-chain structures are tilted with the alkyl chains $\sim 13^{\circ}$ from the surface normal, in contrast to similar structures at $\mathrm{Au}$, which are tilted $\sim 30^{\circ}$. Results from all three characterization methods, although less clearly defined, also indicate a comparable tilt for the shorter chain monolayers. The odd-even effect, observed in contact angle measurements and IRS, is offset by one methylene group relative to monolayers on Au. Both these differences in the structure of $n$-alkanethiolate monolayers on $\mathrm{Ag}$ and $\mathrm{Au}$ point to a difference in the bonding between the head group and the metal. Differences in the substrate crystallography and the electronic properties of the two metals provide a tractable model for the observed differences.

Together, the above results suggest the utility of "thiols on Ag" as models for fundamental studies of complex interfacial processes. In comparison to "thiols on $\mathrm{Au}$ ", the films at $\mathrm{Ag}$ are more densely packed and, as we will show in forthcoming reports, more resistant to ion transport. The latter property is of particular interest to our exploration of such monolayers as applied to the surface modification of electrodes. As a result of the more reactive nature of $\mathrm{Ag}$, however, the reproducible preparation of thiol monolayers is more difficult than at $\mathrm{Au}$. The factors relevant to the formation of these monolayers are under study.

Acknowledgment. M.D.P. gratefully acknowledges the support of a Dow Corning Assistant Professorship. Acknowledgment is also made to the donors of the Petroleum Research Fund, administered by the American Chemical Society. We thank Dr. A. J. Bevolo for the Auger measurements. Ames Laboratory is operated for the U.S. Department of Energy by Iowa State University under Contract No. W-7405-eng-82. This work was supported by the Office of Basic Energy Sciences, Chemical Science Division.

Registry No. Ag, 7440-22-4; $\mathrm{CH}_{3}\left(\mathrm{CH}_{2}\right)_{3} \mathrm{SH}, 109-79-5 ; \mathrm{CH}_{3}\left(\mathrm{CH}_{2}\right)_{4}-$ $\mathrm{SH}, 110-66-7 ; \mathrm{CH}_{3}\left(\mathrm{CH}_{2}\right)_{5} \mathrm{SH}, 111-31-9 ; \mathrm{CH}_{3}\left(\mathrm{CH}_{2}\right)_{6} \mathrm{SH}, 1639-09-4$ $\mathrm{CH}_{3}\left(\mathrm{CH}_{2}\right)_{7} \mathrm{SH}, 111-88-6 ; \mathrm{CH}_{3}\left(\mathrm{CH}_{2}\right)_{8} \mathrm{SH}, 1455-21-6 ; \mathrm{CH}_{3}\left(\mathrm{CH}_{2}\right)_{9} \mathrm{SH}$, 143-10-2; $\mathrm{CH}_{3}\left(\mathrm{CH}_{2}\right)_{10} \mathrm{SH}, 5332-52-5 ; \mathrm{CH}_{3}\left(\mathrm{CH}_{2}\right)_{1} \mathrm{SH}, 112-55-0 ; \mathrm{CH}_{3}$ $\left(\mathrm{CH}_{2}\right)_{12} \mathrm{SH}, 19484-26-5 ; \mathrm{CH}_{3}\left(\mathrm{CH}_{2}\right)_{13} \mathrm{SH}, 2079-95-0 ; \mathrm{CH}_{3}\left(\mathrm{CH}_{2}\right)_{14} \mathrm{SH}$, 25276-70-4; $\mathrm{CH}_{3}\left(\mathrm{CH}_{2}\right)_{15} \mathrm{SH}, 2917-26-2 ; \mathrm{CH}_{3}\left(\mathrm{CH}_{2}\right)_{17} \mathrm{SH}, 2885-00-9$; hexadecane, 544-76-3.

\title{
Upper Rim Calixcrowns: Elucidation of the Mechanism of Conformational Interconversion of Calix[4]arenes by Quantitative 2-D EXSY NMR Spectroscopy
}

\author{
Jan-Dirk van Loon, ${ }^{\dagger}$ Leo C. Groenen, ${ }^{\dagger}$ Sybren S. Wijmenga, ${ }^{\ddagger}$ Willem Verboom, ${ }^{\dagger}$ and \\ David N. Reinhoudt ${ }^{*, \dagger}$
}

Contribution from the Department of Organic Chemistry, University of Twente, 7500 AE Enschede. The Netherlands, and the National HF-NMR Facility, University of Nijmegen, 6525 ED Nijmegen. The Netherlands. Received July 27, 1990

\begin{abstract}
Tetramethoxycalix [4]arenes (4-8) bridged by a polyether chain at the upper rim (upper rim calixcrowns) were synthesized by reaction of 5,17-bis(chloromethyl)-25,26,27,28-tetramethoxycalix[4]arene (3) with poly(oxyethylene) glycols of different length (mono to penta). In $\mathrm{CDCl}_{3}$ solution at $-20^{\circ} \mathrm{C}$, these compounds exist as a mixture of two conformations, viz. the partial cone (P) and the cone $(C)$. The $P / C$ ratio varies between 4.0 and 1.7 depending on the length of the bridge. The upper rim calixcrowns are flexible molecules according to temperature-dependent ${ }^{2} \mathrm{H}$ NMR spectroscopy. For the first time the mechanism of conformational interconversion of calix [4] arenes ( 4 and 5 ) was elucidated by quantitative 2-D EXSY NMR spectroscopy. It proves that there are two different pathways (a slow and a fast process) by which the two $\mathrm{P}$ conformational topomers can interconvert. One interconversion proceeds via $\mathrm{C}$ (slow process), and the other process proceeds most likely via a short-lived 1,3-alternate (A) intermediate (fast process). The rate constants for both pathways were determined: calix [4]crown-2 4, $k_{\mathrm{PA}}=0.58, k_{\mathrm{PC}}=0.054$, and $k_{\mathrm{CP}}=0.27 \mathrm{~s}^{-1}$ at $298 \mathrm{~K}$, and calix [4]crown-3 5, $k_{\mathrm{PA}}=5.4, k_{\mathrm{PC}}=0.07$, and $k_{C P}=0.18 \mathrm{~s}^{-1}$ at $253 \mathrm{~K}$. The overall rate diminishes dramatically going from a nine-atom bridge in 5 to a six-atom bridge in 4. Furthermore, shortening of the bridge has a much larger decelerating effect on the $P \rightarrow A$ than on the $P \rightarrow C$ process.
\end{abstract}

\section{Introduction}

The rational design of specific receptors for the selective binding of (neutral) guests is a rapidly growing field of interest in supramolecular chemistry. 1.2 Therefore, it is important to develop three-dimensional building blocks for the attachment of functional groups that can be oriented in space in such a way that they can form a suitable binding site. In particular, calix [4]arene 1 (Chart 1), a cyclic tetramer composed of phenolic units which are linked via the ortho positions by methylene bridges, ${ }^{3}$ is recognized to be such an important molecular building block. Calix[4]arene is readily available from cheap starting materials, ${ }^{4}$ and it can be

\footnotetext{
University of Twente.

: University of Nijmegen.
}

easily functionalized at the phenolic $\mathrm{OH}$ groups (lower rim $)^{3}$ as well as at the para positions of the phenol rings (upper rim). ${ }^{3.5}$

(1) (a) Lehn, J.-M. Angew. Chem, 1988, 100, 91-119. (b) Cram, D. J. Angew. Chem. 1988, 100, 1041-1052. (c) Diederich, F. Angew. Chem. 1988, 100, 372-396. (d) Collet, A. Tetrahedron 1987, 43, 5725-5759. (e) Koga, K.; Odashima, K. J. Inclusion Phenom. Mol. Recognit. Chem. 1989, 7, 53-60. (f) Reinhoudt, D. N.; den Hertog, Jr., H. J. Bull. Soc. Chim. Belg. 1988, 97, 645-653. (g) Reinhoudt, D. N.; Dijkstra, P. J. Pure Appl. Chem. 1988, 60, $477-482$.

(2) (a) Weber, E. Progress in Macrocyclic Chemistry (Synthesis of Macrocycles, the Design of Selective Complexing Agents); Izatt, R. M., Christensen, J. J., Eds.; John Wiley \& Sons: New York, 1989; Vol. 3, pp 337-419. (b) Hamilton, A. D.; Muehidorf, A.; Chang, S.-K.; Pant, N.; Goswami, S.; van Engen, D. J. Inclusion Phenom. Mol. Recognit. Chem. 1989, 7, 27-38. (c) Rebek, Jr. J Angew Chem Int Ed. Engl 1990, 29, 245-255. (d) Zimmerman, S. C.; Wu, W. J. Am. Chem. Soc. 1989, 111, 8054-8055. 
Chart I
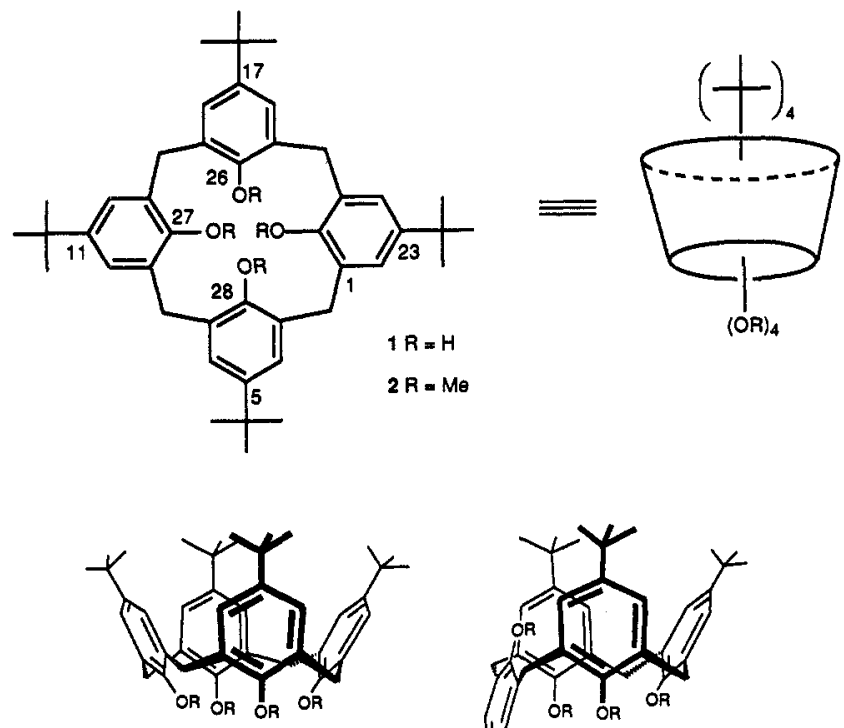

Cone

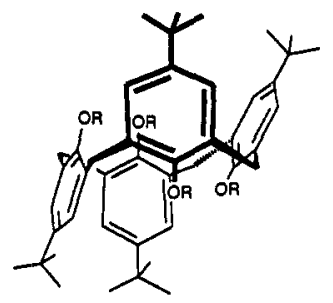

1,2-Alternate
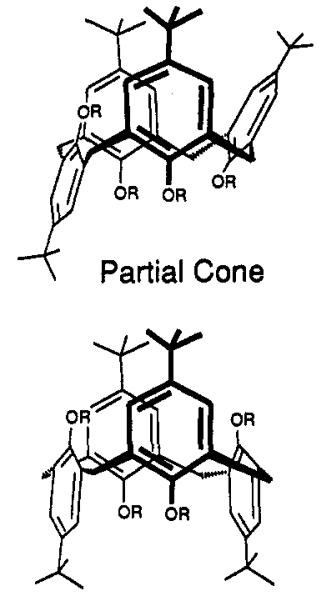

1,3-Alternate

One of the most important properties of calix [4]arene, which renders the molecule rather unusual, is the ability to adopt four different extreme conformations (Chart I). This is an advantage, since it enlarges the number of potentially useful geometries of the building block. However, this also requires the ability to control the conformation of calix[4]arene. As an example we have recently designed a potassium selective lower rim calixcrown ether in a fixed partial cone conformation, because this conformation is optimally preorganized for the complexation of spherical cations. ${ }^{6}$

When all four phenolic $\mathrm{OH}$ groups of calix[4]arene are replaced by large substituents, conformationally fixed derivatives are obtained, generally as a cone, partial cone, 1,3-alternate, or a mixture of these conformations. ${ }^{3}$ Unsubstituted calix [4]arenes and calix [4]arenes that only bear small substituents at the lower rim (like methoxy groups, 2) are conformationally mobile, ${ }^{7,8}$ since small groups can rotate through the calixarene annulus. In principle, the ratio of the different conformations of these compounds is determined by the relative free energies. Despite all the work on calix [4]arenes, the mechanism of conformational interconversion is still not unravelled.

(3) Gutsche, C. D. Calixarenes, Monographs in Supramolecular Chemistry; Stoddart, J. F., Ed.; The Royal Society of Chemistry: Cambridge, 1989; Vol. 1 .

(4) Gutsche, C. D.; Iqbal, M.; Stewart, D. J. Org. Chem. 1986, 51, $742-745$.

(5) (a) van Loon, J.-D.; Arduini, A.; Verboom, W.; Ungaro, R.; van Hummel, G. J.; Harkema. S.; Reinhoudt, D. N. Tetrahedron Lett. 1989, 30 , 2681-2684. (b) van Loon, J.-D.; Arduini, A.; Coppi, L.; Verboom, W.; Pochini, A.: Ungaro, R.; Harkema, S.; Reinhoudt, D. N. J. Org. Chem. 1990, $55,5639-5646$

(6) Ghidini, E.; Ugozzoli, F.; Ungaro, R.; Harkema, S.; El-Fadl, A. A.; Reinhoudt, D. N. J. Am. Chem. Soc. 1990, 112, 6979-6985.

(7) Happel, G.; Mathiasch, B.; Kämmerer, H. Makromol. Chem. 1975, 176, 3317-3334

(8) Gutsche, C. D.; Dhawan, B.; Levine, J. A.; No, K. H.; Bauer, L. J. Tetrahedron 1983, 39, 409-426.

Scheme I

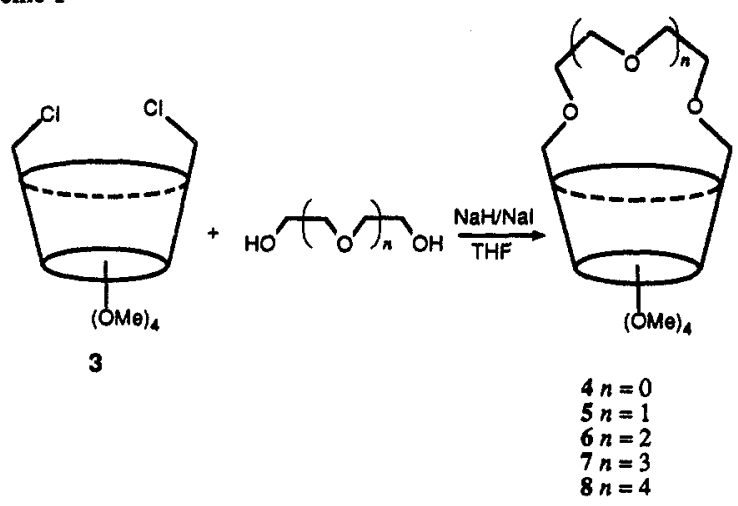

The "unsubstituted" calix[4]arenes (e.g., 1) are flexible and show only a rigid cone conformation (at the ${ }^{1} \mathrm{H}$ NMR time scale) upon lowering of the temperature, due to the intramolecular $\mathrm{H}$ bonding. ${ }^{7}$ From temperature-dependent ${ }^{1} \mathrm{H}$ NMR spectra the activation parameters of the conformational inversion process (cone to cone) were determined by using line shape analysis $7,9,10$ and coalescence temperatures, " but there is still no general agreement on the mechanism of conformational interconversion. Kämmerer et al. ${ }^{7}$ suggested a 1,3-alternate conformation as an intermediate, which can revert either to the original cone conformation or to its mirror image (i.e., the "inverted cone"). Gutsche et al. proposed a continuous-chain pathway, in which the aryl groups swing through the annulus in sequence." Shinkai et al. have concluded from line shape analysis experiments that the "cone-to-alternate transition" does not exist, and they have proposed a direct cone-to-cone inversion. ${ }^{10}$ We recently suggested a partial cone conformation as a key intermediate for $p$-tetramethylcalix [4]arene on the basis of molecular dynamic studies. ${ }^{12}$ Finally, Keller et al. ${ }^{13}$ suggested, on the basis of IR experiments, the possibility that no inversion of the calixarene takes place but only a loss of the methylene symmetry by an increased rocking motion.

We feel that until now it is not possible to exclude any one of the proposed pathways, since the intermediates involved may have such a high energy compared with the cone conformation that they cannot be detected by ${ }^{1} \mathrm{H}$ NMR spectroscopy, which has only an energy window of about $3 \mathrm{kcal} \mathrm{mol}^{-1}$.

Calix [4] arenes bearing four methoxy groups ${ }^{14}$ are also conformationally flexible, but they behave differently from the unsubstituted analogues, since $H$ bonds that would favor the cone are absent. Gutsche et al. ${ }^{8}$ have proposed that at low temperatures compound 2 exists as a mixture of two partial cone conformers, having an "inside" and an "outside" methoxy group. ${ }^{15}$ Furthermore, Shinkai et al. have claimed that $p$-nitrotetramethoxycalix [4] arene exists as a mixture of different conformations, although the conformations were not specified. ${ }^{16}$

This paper describes for the first time the unequivocal, quantitative elucidation of the mechanism of conformational interconversion of calix [4] arenes containing four methoxy groups

(9) Munch, J. H. Makromol. Chem. 1977, 178, 69-74. (Gutsche proposed that the compound that was used in this article was probably the cyclic octamer: Gutsche, C. D.; Dhawan, B.; No, K. H.; Muthukrisnan, R. J. Am. Chem. Soc. 1981, 103, 3782-3792.)

(10) Araki, K.; Shinkai, S.; Matsuda, T. Chem. Lett. 1989, 581-584.

(11) Gutsche, C. D.; Bauer, L. J. J. Am. Chem. Soc. 1985, 107, 6052-6059.

(12) Grootenhuis, P. D. J.; Kollman, P. A.; Groenen, L. C.; Reinhoudt, D. N.; van Hummel, G. J.; Ugozzoli, F.; Andreetti, G. D. J. Am. Chem. Soc. $1990,112,4165-4176$.

(13) Keller, S. W.; Schuster, G. M.; Tobiason, F. L. Polym. Mater. Sci. Eng. 1987, 57, 906-910.

(14) Very recently Shinkai claimed that also ethoxy groups can rotate through the ring annulus: Araki, K.; Iwamoto, K.; Shinkai, S.; Matsuda, T. Chem. Lett. 1989, 1747-1750.

(15) We prove that this is not correct in the following paper in this issue.

(16) Shinkai, S.; Arimura, T.; Araki, K.; Kawabata, H.; Satoh, H.; Tsubaki, T.; Manabe, O.; Sunamoto, J. J. Chem. Soc., Perkin Trans. $l$ 1989, 2039-2045. 


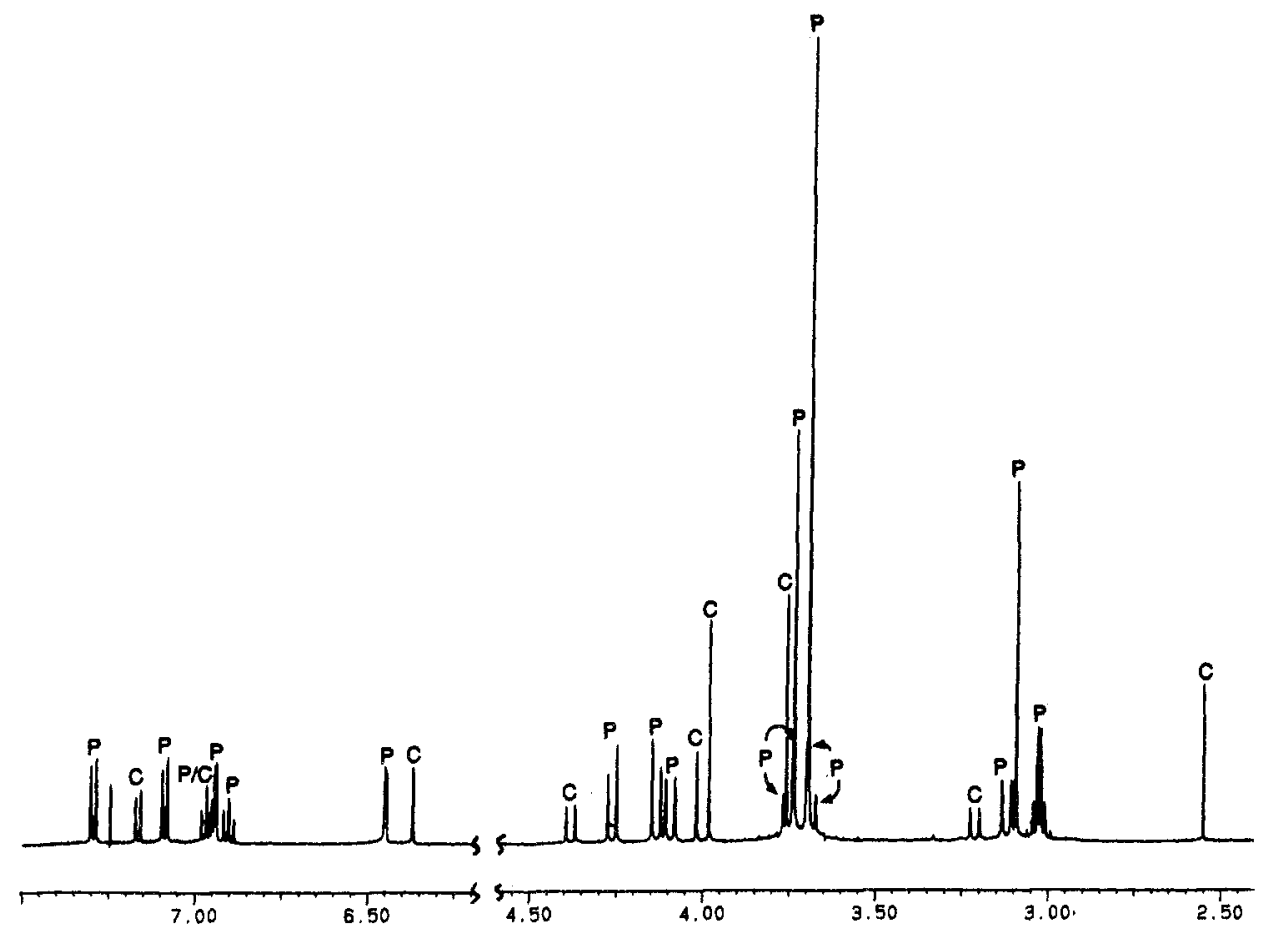

Figure 1. 'H NMR spectrum ( $500 \mathrm{MHz})$ of calix[4]crown-2 4 at $298 \mathrm{~K}$.

at the lower rim, that are partly rigidified by bridges at the upper rim in order to limit the number of possible conformational transitions.

\section{Results and Discussion}

In tetramethoxycalix [4]arene 2 all four anisole rings are free to rotate, and we decided to study the mechanism of conformational interconversion for a tetramethoxycalix [4] arene, of which two opposite anisole rings are rigidified by means of a poly(oxyethylene) bridge, connecting the two opposite para positions (compounds 4-8). This has the advantage that one of the four possible conformations, viz., the 1,2-alternate conformation, is eliminated as an intermediate. Furthermore, conformational transitions are confined to the rotation of the two free anisole rings, and finally the influence of the rigidity of the linked anisole rings on the rate of the conformational interconversion processes can be studied by variation of the length of the bridge.

Reaction of 5,17-bis(chloromethyl)-25,26,27,28-tetramethoxycalix [4]arene $(3)^{5}$ with poly(oxyethylene) glycols of different length by using $\mathrm{NaH} / \mathrm{NaI} / \mathrm{THF}$ under high dilution conditions afforded a series of calix [4]crowns 4-8 having a crown ether bridge at the upper rim in 11-95\% yield (Scheme I). The upper rim calix [4]crowns 4-8 are the first examples of calix[4]arenes bearing a bridge that contains heteroatoms on the upper rim. Böhmer et al. recently published a series of tetrahydroxycalix [4]arenes having two opposite para positions connected by an aliphatic chain. ${ }^{17}$ Böhmer's compounds are conformationally rigid and show a cone conformation in the solid state as well as in solution.

The ${ }^{1} H$ NMR spectra of upper rim calix [4]crown ethers 5-8, however, show broad peaks indicating that slow conformational interconversion occurs. All the spectra are very similar, and the signals become sharp upon lowering the temperature to $-20^{\circ} \mathrm{C}$ (at $200 \mathrm{MHz}$ ), except for the calix[4]crown-2 4, which has the shortest bridge (six atoms). This compound shows sharp signals already at room temperature. This indicates that conformational interconversions, that take place in 4 (vide infra), are slower than for the other calixcrowns. The $500-\mathrm{MHz}{ }^{1} \mathrm{H}$ NMR spectrum (Figure 1) reveals that in solution 4 exists as a mixture of two conformations, ${ }^{18}$ viz., the partial cone $(\mathrm{P})$ and the cone (C) (ratio

(17) Goldmann, H.; Vogt, W.; Paulus, E.; Böhmer, V. J. Am. Chem. Soc. 1988, $110,6811-6817$.

(18) We will show that even more conformations do exist (vide infra).
Chart II
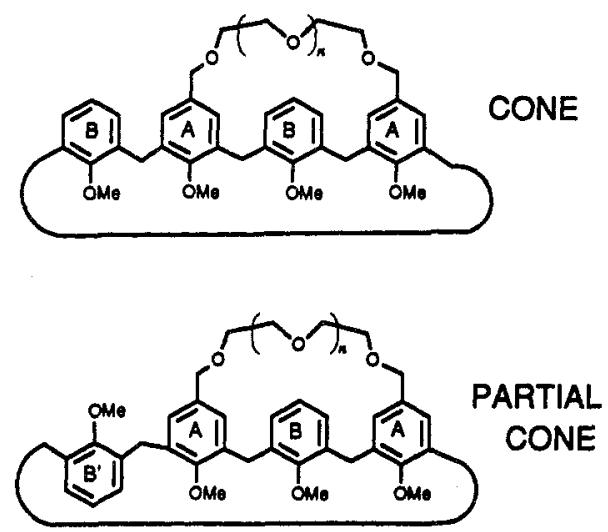

$P / C=4.0$ ). The cone conformation $C$ has two planes of symmetry, which is reflected in the ${ }^{1} \mathrm{H}$ NMR spectrum. The aromatic protons of both A rings (Chart II) appear as a singlet at $\delta 6.38$. Both $B$ rings are equivalent and exhibit a doublet for the meta protons at $\delta 7.18(J=7.5 \mathrm{~Hz})$ and a triplet for the para protons at $\delta 6.96$. The methoxy groups appear as two singlets at $\delta 3.77$ (A) and 3.99 (B), respectively. The benzylic protons show a singlet at $\delta 4.03$, and also the ethylene bridge protons appear as a singlet at rather high field $(\delta 2.56)$, due to the shielding effect of the B rings. Finally, the AX system of the methylene bridges, typical for the cone conformation, is located at $\delta 4.39$ and $3.22(J=13.0$ $\mathrm{Hz}$ ). The partial cone conformation $P$ has only one plane of symmetry, and consequently the aromatic protons of the $A$ rings are present as an $\mathrm{AB}$ system at $\delta 6.46$ and $6.95(J=1.9 \mathrm{~Hz})$. The $B$ and $B^{\prime}$ rings are not equivalent and exhibit two doublets for the meta protons at $\delta 7.10(\mathrm{~B}, J=7.5 \mathrm{~Hz})$ and $7.31\left(\mathrm{~B}^{\prime}, J=7.5\right.$ $\mathrm{Hz}$ ) and two triplets for the para protons at $\delta 6.91(\mathrm{~B})$ and 6.98 $\left(B^{\prime}\right)$. The methoxy groups of the $A, B$, and $B^{\prime}$ rings appear as three singlets in the ratio of $2: 1: 1$ at $\delta 3.71(\mathrm{~A}), 3.75(\mathrm{~B})$, and $3.11\left(B^{\prime}\right)$, clearly showing that the methoxy group of the $B^{\prime}$ ring is in the cavity. In contrast to $\mathrm{C}$, the bridge protons in $\mathrm{P}$ are no longer equivalent. This explains the $\mathrm{AB}$ system of the benzylic protons $(\delta 4.27$ and $4.14, J=12.5 \mathrm{~Hz})$ and the multiplet of the ethylene bridge protons at $\delta 3.05-2.95$. The methylene bridge protons of $P$ show an AX system at $\delta 4.10$ and $3.13(J=13.5$ $\mathrm{Hz})$ and an $\mathrm{AB}$ system at $\delta 3.76$ and $3.70(J=13.5 \mathrm{~Hz})$. 


\section{Chart III}

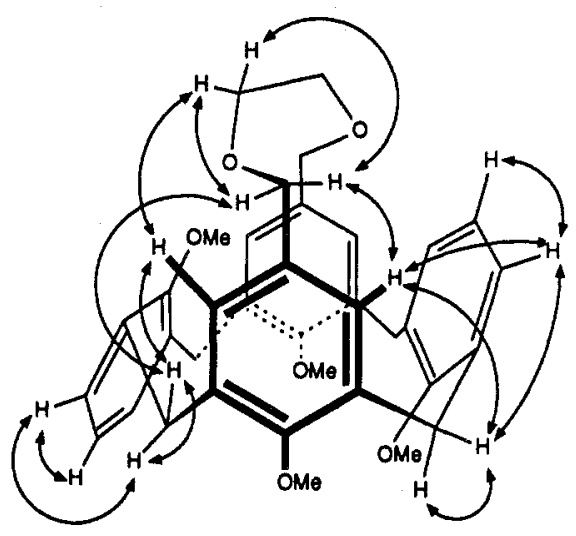

Partial Cone (P)

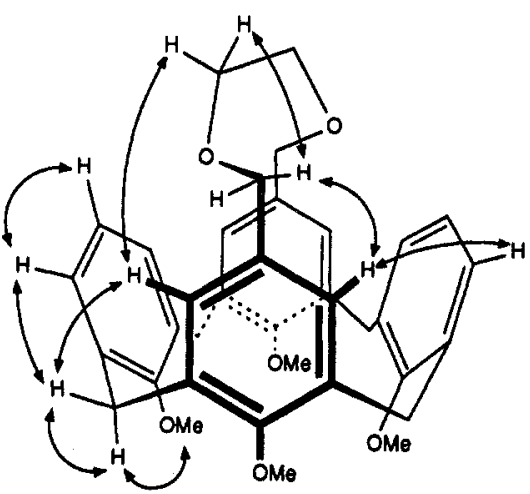

Cone (C)

Table I. Partial Cone/Cone Ratios, Mass, and 'H NMR Data of Upper Rim Calix [4]crowns 4-8

\begin{tabular}{|c|c|c|c|c|c|}
\hline compd & $4^{a}$ & $5^{b}$ & $6^{b}$ & $7^{b}$ & $8^{b}$ \\
\hline $\begin{array}{l}\text { partial cone/cone ratio } \\
\text { mass spectra (EI) }\end{array}$ & $4.0 \pm 0.4$ & $2.3 \pm 0.2$ & $1.9 \pm 0.1$ & $1.7 \pm 0.1$ & $1.7 \pm 0.1$ \\
\hline $\begin{array}{l}\mathrm{M}^{+} \text {(calcd) } \\
\text { 'H NMR of cone } \\
\text { conformations. } \delta\end{array}$ & $566.274(566.267)$ & $610.301(610.293)$ & $654.330(654.319)$ & $698.354(698.346)$ & $742.375(742.372)$ \\
\hline $\operatorname{ArH}(s, A)$ & 6.38 & 6.38 & 6.37 & 6.36 & 6.36 \\
\hline $\mathrm{ArH}\left(\mathrm{d}, J, \mathrm{~Hz}, \mathrm{~B}_{\mathrm{meta}}\right)$ & $7.18(7.5)$ & $7.27(8.0)$ & $7.21(7.5)$ & $7.21(7.4)$ & $7.17(6.8)$ \\
\hline $\operatorname{ArH}\left(t, B_{\text {para }}\right)$ & 6.96 & $7.1-7.0$ & $7.05-6.95$ & 6.99 & $7.05-6.95$ \\
\hline $\mathrm{OMe}(\mathrm{s}, A)$ & 3.77 & 3.87 & 3.77 & 3.76 & 3.73 \\
\hline $\mathrm{OMe}(\mathrm{s}, \mathrm{B})$ & 3.99 & 4.02 & 3.95 & 3.95 & 3.93 \\
\hline $\mathrm{ArCH}_{2} \mathrm{O}(\mathrm{s})$ & 4.03 & 4.19 & 4.13 & 4.12 & 4.08 \\
\hline $\mathrm{OCH}_{2} \mathrm{CH}_{2} \mathrm{O}$ & $2.56(\mathrm{~s})$ & $3.7-3.0(\mathrm{~m})^{c}$ & $3.7-3.0(\mathrm{~m})^{c}$ & $3.7-3.0(\mathrm{~m})^{c}$ & $3.7-3.0(\mathrm{~m})^{c}$ \\
\hline $\begin{array}{l}\mathrm{ArCH}_{2} \mathrm{Ar}(\mathrm{AX} \mathrm{q}, J, \mathrm{~Hz}) \\
\text { ' } \mathrm{H} \text { MR of partial cone }\end{array}$ & 4.39 and $3.22(13.0)$ & 4.43 and $3.30(13.1)$ & 4.41 and $3.24(13.7)$ & 4.41 and $3.24(13.6)$ & 4.35 and $3.23(13.5)$ \\
\hline $\begin{array}{l}\text { conformations, } \delta \\
\text { ArH (AB q, } J, \mathrm{~Hz}, \mathrm{~A})\end{array}$ & 6.95 and $6.46(1.9)$ & 7.06 and $6.46(<1)$ & 6.96 and $6.41(<1)$ & 6.91 and $6.43(1.6)$ & 6.91 and $6.40(<1)$ \\
\hline $\mathrm{ArH}\left(\mathrm{d}, J, \mathrm{~Hz}, \mathrm{~B}_{\text {meta }}\right)$ & $7.10(7.5)$ & $7.20(7.2)$ & $7.13(7.3)$ & $7.13(7.3)$ & $7.13(8.0)$ \\
\hline $\mathrm{ArH}\left(\mathrm{d}, J, \mathrm{~Hz}, \mathrm{~B}_{\text {meta }}^{\prime}\right)$ & $7.31(7.5)$ & $7.41(7.4)$ & $7.33(7.5)$ & $7.33(7.5)$ & $7.32(7.6)$ \\
\hline ArH $\left(t, B_{\text {para }}\right)$ & 6.91 & $7.1-7.0$ & $7.05-6.90$ & 6.99 & $7.05-6.95$ \\
\hline $\mathrm{ArH}\left(\mathrm{t}, \mathrm{B}_{\text {para }}^{\prime}\right)$ & 6.98 & $7.1-7.0$ & $7.05-6.90$ & 6.99 & $7.05-6.95$ \\
\hline $\mathrm{OMe}(\mathrm{s}, \mathrm{A})$ & 3.71 & 3.76 & 3.66 & 3.67 & 3.67 \\
\hline $\mathrm{OMe}(\mathrm{s}, \mathrm{B})$ & 3.75 & 3.82 & 3.73 & 3.73 & 3.73 \\
\hline $\mathrm{OMe}\left(\mathrm{s}, \mathrm{B}^{\prime}\right)$ & 3.11 & 3.09 & 3.02 & 3.01 & 3.00 \\
\hline $\mathrm{ArCH}_{2} \mathrm{O}(\mathrm{AB} \mathrm{q}, J, \mathrm{~Hz})$ & 4.27 and $4.14(12.5)$ & 4.45 and $4.35(12.4)$ & 4.40 and $4.30(12.5)$ & 4.41 and $4.29(12.2)$ & 4.35 and $4.21(12.3)$ \\
\hline $\mathrm{OCH}_{2} \mathrm{CH}_{2} \mathrm{O}(\mathrm{m})$ & $3.05-2.95$ & $3.7-3.0^{c}$ & $3.7-3.0^{c}$ & $3.7-3.0^{c}$ & $3.7-3.0^{c}$ \\
\hline $\operatorname{ArCH}_{2} \mathrm{Ar}(\mathrm{AX} \mathrm{q}, J, \mathrm{~Hz})$ & 4.10 and $3.13(13.5)$ & 4.15 and $3.24(14.0)$ & 4.07 and $3.14(13.7)$ & 4.06 and $3.16(13.3)$ & 4.05 and $3.15(14.0)$ \\
\hline $\mathrm{ArCH}_{2} \mathrm{Ar}(\mathrm{AB} \mathrm{q}, J, \mathrm{~Hz})$ & 3.76 and $3.70(13.5)$ & $3.8-3.6^{c}$ & $3.8-3.6^{c}$ & $3.8-3.6^{\mathrm{c}}$ & $3.8-3.6^{c}$ \\
\hline
\end{tabular}

${ }^{a}$ Recorded at $298 \mathrm{~K}$. ${ }^{b}$ Recorded at $253 \mathrm{~K}$. ${ }^{c}$ Cannot be assigned.

Additional evidence for the existence of the two conformations was obtained by 2-D COSY and NOESY NMR techniques. The COSY NMR spectrum clearly shows the coupling between the methylene bridge protons, and this was used to assign the meta and para protons of the $B$ and $B^{\prime}$ rings of $P$. Most of the structural evidence was obtained from the NOESY spectrum. ${ }^{19,20}$ Chart III shows all the observed NOE interactions for both conformations.

The ' $\mathrm{H}$ NMR spectra of compounds 5-8 at $-20^{\circ} \mathrm{C}$ are very similar to the 'H NMR spectrum of calix[4]crown-2 4, all showing a mixture of $\mathrm{P}$ and $\mathrm{C}$ (Table $\mathrm{I}$ ). The ratio $\mathrm{P} / \mathrm{C}$ decreases with larger bridges and goes to a plateau value (Table I). Squeezing the two anisole rings together by shortening of the bridge apparently decreases the relative thermodynamic stability of $C$.

Dynamic NMR Studies. Since $P$ and $C$ can be clearly distinguished in the 'H NMR spectrum, it should be possible to measure the rate constants of conformational interconversion. In principle it is possible to determine rate constants by NMR line shape

(19) The pulse sequence of the NOESY and EXSY (vide infra) NMR experiments are identical.

(20) The NOE cross peaks of the calixcrown-3 5 showed positive sign phase with regard to the positively phased diagonal peaks, as is expected for small molecules that are in the slow tumbling limit. analysis, but this method cannot discriminate between different exchange pathways (vide infra). We decided to perform the 2-D chemical exchange (2-D EXSY) NMR experiments, not only because this method gives rate constants but also because it allows one to determine the different exchange pathways. It is possible to record a series of different 2-D EXSY spectra with different magnitudes of the mixing time $\tau_{\mathrm{m}}$. The rate of change of the cross peak intensities as a function of $\tau_{m}$ reflects the exchange rate constant. Very recently several groups have used the method of Abel et al. ${ }^{21}$ to study intra- and intermolecular exchange processes in [8]annulenes ${ }^{22}$ and vanadate complexes, ${ }^{23}$ respectively, by using only one value of $\tau_{\mathrm{m}}$. However, we preferred to measure 2-D EXSY spectra at different mixing times, because it allows one to find direct evidence for the existence and significance of indirect exchange processes. In addition, it provides a more direct estimate of experimental errors in the determined rate constants.

(21) (a) Abel, E. W.; Coston, T. P. J.; Orrell, K. G.; Šik, V.; Stephenson, D. J. Magn. Reson. 1986, 70, 34-53. (b) Perrin, C. L.; Gipe, R. K. J. Am. Chem. Soc. 1984, 106, 4036-4038.

(22) Paquette, L. A.; Wang, T.-Z.; Luo, J.; Cottrell, C. E.; Clough, A. E.; Anderson, L. B. J. Am. Chem. Soc. 1990, 112, 239-253.

(23) Crans, D. C.; Rithner, C. D.; Theisen, L. A. J. Am. Chem. Soc. 1990 $112,2901-2908$. 

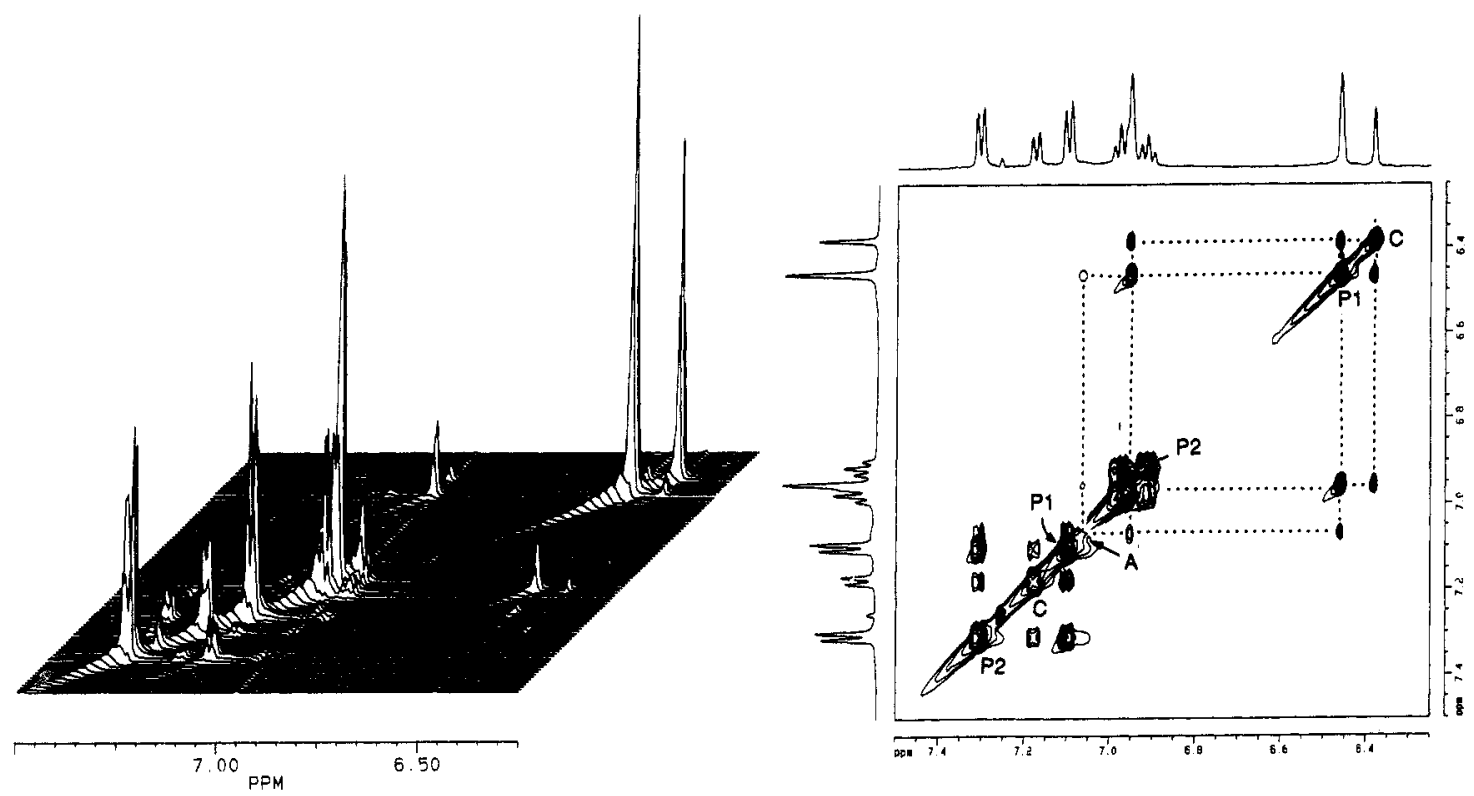

Figure 2. Contour and stack plot of the aromatic region of calix [4]crown-2 $4\left(\tau_{\mathrm{m}}=0.6 \mathrm{~s}\right)$ (the contour plot only shows positive ( $=$ exchange) cross peaks for clarity).

In order to get an idea of the different exchange pathways that play a role, it is worthwhile first to interpret the 2-D EXSY NMR spectrum of calix[4]crown-2 4 at one particular $\tau_{m}(0.6 \mathrm{~s})$ qualitatively. Figure 2 shows a contour plot of the aromatic region. The diagonal shows signals from $\mathrm{P}$ and $\mathrm{C}$, and a set of cross peaks can be seen to result from the transfer of magnetization between $P$ and $C$ (and vice versa), indicating that $P$ and $C$ interconvert. However, surprisingly also cross peaks are present that transfer magnetization between two $P$ sites. It should be noted that two $P$ conformations $\left(P_{a}\right.$ and $\left.P_{b}\right)$ exist, which can be regarded as conformational topomers. ${ }^{24}$ These topomers cannot be distinguished in the ' $H$ NMR spectrum, but in principle they can interconvert, resulting in a cross peak between the exchanging sites. The observed cross peak could be an indirect exchange cross peak, resulting from the $\mathrm{P}_{\mathrm{a}} \rightleftarrows \mathrm{C} \rightleftarrows \mathrm{P}_{\mathrm{b}}$ process. However, an indirect exchange process via $\mathrm{C}$ would not account for the high intensities of the PP cross peaks (see stack plot in Figure 2). Therefore, a second pathway of conformational interconversion between the $\mathbf{P}$ topomers must exist, which is faster than the process via $C$. It might be possible that this is a concerted process, in which the $B$ and $B^{\prime}$ anisole rings rotate through the calixarene annulus simultaneously, resulting in a direct magnetization transfer between the two $P$ sites. The observed linear relation between PP cross peak intensities and $\tau_{\mathrm{m}}$ (vide infra) suggests indeed that the intensity results from a direct exchange process. However, it is unlikely that a process, in which two methoxy groups have to move through a small annulus, would be faster than the process $P \rightleftharpoons C$ in which only one methoxy group rotates. Therefore, we concluded that the second pathway proceeds via an intermediate which is too high in energy to be detected in the ${ }^{1} \mathrm{H}$ NMR spectrum (>2-3 kcal mol-1 higher than P). Since the 1,2-alternate conformation is not possible because of the bridge, we propose that the intermediate is a 1,3-alternate conformation (A). The existence of $\mathrm{A}$ as an intermediate would also explain the third set of very weak cross peaks that can be observed between sites of $P$ and positions on the diagonal of very low intensity (e.g., at $\delta 7.07){ }^{25}$

For the conformational interconversion processes we can write the following equilibrium

$$
\mathrm{C} \underset{k_{\mathrm{PC}}}{\stackrel{k_{\mathrm{CP}}}{\rightleftarrows}} \mathrm{P} \underset{k_{\mathrm{AP}}}{\stackrel{k_{\mathrm{PA}}}{\rightleftarrows}} \mathrm{A}
$$

(24) Binch, B.; Eliel, E. L.; Kessler, H. Angew. Chem. 1971, 83, 618-619. (25) In the region of $\delta 4.5-2.3$ a similar set of small cross peaks are observed for the signals of the methoxy groups and for signals of the ethylene bridge protons. where $k_{\mathrm{ij}}$ is the rate constant for the interconversion from $\mathrm{i}$ to $\mathrm{j}$.

Because it has only one plane of symmetry the partial cone $P$ has two (coupled) sites (P1 and P2) that exchange with the sites of $A$ and $C$. Therefore, the system can be described as a four-site exchange process<smiles>[Y14]1=[W]=[W]=[W]=1</smiles>

where $M_{\mathrm{i}}$ is the deviation from equilibrium of the magnetization of site $i$. It is important to notice that both equilibria (1) and (2) do not distinguish between the different conformational topomers $P_{a}$ and $P_{b}$, because $P_{a}$ and $P_{b}$ cannot be detected separately in the 1-D and 2-D NMR spectra. The P1 and P2 sites both consist of $P_{a}$ magnetization (50\%) and $P_{b}$ magnetization (50\%). Therefore, the rate constants are defined as in equilibrium 1 . The topomers are only useful to visualize the different pathways of conformational interconversion. Furthermore, the $P 1$ and $P 2$ sites are coupled, which means that the interconversion $C \rightarrow P$ results in the simultaneous transfer of magnetization from $C$ to both $P 1$ and P2. (The same holds for $\mathrm{A} \rightarrow \mathrm{P}, \mathrm{P} \rightarrow \mathrm{C}$, and $\mathrm{P} \rightarrow \mathrm{A}$ transitions.) The following set of four coupled differential equations describes the exchange process. Already at very short

$$
\begin{gathered}
\delta M_{\mathrm{C}} / \delta t=-k_{\mathrm{CP}} M_{\mathrm{C}}+k_{\mathrm{PC}}\left(M_{\mathrm{P} 1}+M_{\mathrm{P} 2}\right) \\
\delta M_{\mathrm{P} 1} / \delta t=1 / 2 k_{\mathrm{CP}} M_{\mathrm{C}}-k_{\mathrm{PC}} M_{\mathrm{P} 1}+1 / 2 k_{\mathrm{AP}} M_{\mathrm{A}}-k_{\mathrm{PA}} M_{\mathrm{P} 1} \\
\delta M_{\mathrm{P} 2} / \delta t=1 / 2 k_{\mathrm{CP}} M_{\mathrm{C}}-k_{\mathrm{PC}} M_{\mathrm{P} 2}+1 / 2 k_{\mathrm{AP}} M_{\mathrm{A}}-k_{\mathrm{PA}} M_{\mathrm{P} 2} \\
\delta M_{\mathrm{A}} / \delta t=-k_{\mathrm{AP}} M_{\mathrm{A}}+k_{\mathrm{PA}}\left(M_{\mathrm{P} 1}+M_{\mathrm{P} 2}\right)
\end{gathered}
$$

mixing times we found that the cross peak intensities between $P$ and $A$ reach a stationary value, while both the PP and PC cross peaks are virtually linearly dependent on $\tau_{m}$ (see Figure 3 ), which means that $\mathrm{A}$ is a short-lived intermediate. Since $M_{\mathrm{A}}$ is constant at mixing times that are used in the experiments, $\delta M_{\mathrm{A}} / \delta t=0$, and the set of eq 3 can be written in terms of a three-site exchange process, in which the exchange between $P_{1}$ and $P_{2}$ becomes a pseudodirect exchange process. ${ }^{26}$ From the general theory of exchange spectroscopy ${ }^{27}$ the solution of this set of three coupled

(26) Because the intensity of the stationary value of A contributes less than $2 \%$ to the intensity of the diagonal signal of $\mathrm{P}, \mathrm{A}$ is present in solution to less than $2 \%$, and $\mathrm{P}$ can be approximated by its diagonal value. 
Table II. Rate Data of Calix[4]crown-2 $4^{a}$ and Calix [4]crown-3 $5^{b}$

\begin{tabular}{cccccc} 
& \multicolumn{2}{c}{ calix[4]crown-2 4} & & \multicolumn{2}{c}{ calix[4]crown-3 5 } \\
\cline { 2 - 3 } \cline { 5 - 6 } XY & \multicolumn{1}{c}{$k_{\mathrm{XY}}\left(\mathrm{s}^{-1}\right)$} & $a^{c}\left(\mathrm{~s}^{-1}\right)$ & & $k_{\mathrm{XY}}\left(\mathrm{s}^{-1}\right)$ & $a^{c}\left(\mathrm{~s}^{-1}\right)$ \\
\hline $\mathrm{PA}$ & $0.58 \pm 0.04$ & $0.29 \pm 0.02$ & & $5.4 \pm 0.5$ & $2.71 \pm 0.25$ \\
$\mathrm{PC}$ & $0.054 \pm 0.010$ & $0.054 \pm 0.010$ & & $0.07 \pm 0.04$ & $0.07 \pm 0.04$ \\
$\mathrm{CP}$ & $0.27 \pm 0.05$ & $0.13 \pm 0.02$ & & $0.18 \pm 0.02$ & $0.09 \pm 0.01$ \\
\hline
\end{tabular}

${ }^{a}$ Measured at $298 \mathrm{~K} .{ }^{b}$ Measured at $253 \mathrm{~K}$. ${ }^{c} a=L_{\mathrm{kl}}$ (eq 5 ).

differential equations can be written in a matrix notation as $\mathbf{M}$ $=\mathbf{M}_{0} \exp \left(\mathbf{L} \tau_{\mathrm{m}}\right)$ where $\mathbf{M}_{0}$ is the matrix of deviations from equilibrium of the magnetizations at NOESY mixing time $\tau_{\mathrm{m}}=$ 0 . The exchange matrix used is then

$\mathbf{L}=$

$$
\left|\begin{array}{lll}
-1 / T_{1 C}-k_{\mathrm{CP}} & k_{\mathrm{PC}} & k_{\mathrm{PC}} \\
1 / 2 k_{\mathrm{CP}} & -1 / T_{1 \mathrm{P} 1}-\left(k_{\mathrm{PC}}+1 / 2 k_{\mathrm{PN}}\right) & 1 / 2 k_{\mathrm{PA}} \\
1 / 2 k_{\mathrm{CP}} & 1 / 2 k_{\mathrm{PA}} & -1 / T_{1 \mathrm{P} 2}-\left(k_{\mathrm{PC}}+1 / 2 k_{\mathrm{PA}}\right)
\end{array}\right|
$$

where $T_{1 \mathrm{i}}$ is the longitudinal relaxation. Since for small $\tau_{\mathrm{m}}, \mathbf{M}$ $\cong \mathbf{M}_{0}\left(1+\mathbf{L} \tau_{m}+1 / 2\left(\mathbf{L} \tau_{m}\right)^{2}+\ldots\right)$ we obtain

$$
\begin{gathered}
a_{\mathrm{kk}}=1+L_{\mathrm{kk}} \tau_{\mathrm{m}}+\sum_{\mathrm{j}} L_{\mathrm{kj}} L_{\mathrm{jk}} \tau_{\mathrm{m}}{ }^{2}+\ldots \\
a_{\mathrm{k} l}=L_{\mathrm{k} 1} \tau_{\mathrm{m}}+\sum_{\mathrm{j}} L_{\mathrm{kj}} L_{\mathrm{j} l} \tau_{\mathrm{m}}{ }^{2}+\ldots
\end{gathered}
$$

with

$$
\begin{aligned}
I_{\mathrm{kk}} & =a_{\mathrm{kk}} M_{\mathrm{k} 0} \\
I_{\mathrm{kl}} & =a_{\mathrm{kl}} M_{10}
\end{aligned}
$$

where $I_{\mathrm{ij}}$ is an element of the intensity matrix $I$. We can now derive that

$$
I_{\mathrm{kl}} / I_{\mathrm{l}} \cong L_{\mathrm{k} l} \tau_{\mathrm{m}}+\tau_{\mathrm{m}}^{2}\left(1 / 2 \sum_{\mathrm{j}} L_{\mathrm{kj}} L_{\mathrm{jl}}-L_{\mathrm{kl}} L_{\mathrm{ll}}\right)+\ldots
$$

The quadratic terms correspond to indirect exchange processes, in which longitudinal magnetization is transferred from $k$ via $j$ to $1^{27}$ It can be shown that the $T_{1}$ relaxation can be eliminated from this relation if we assume that each proton has the same $T_{1}$ value. We indeed have found that $T_{1}$ values of all the aromatic protons were equal within the experimental error. Therefore, the curve $I_{\mathrm{kl}} / I_{11}$ vs $\tau_{\mathrm{m}}$ is exclusively determined by exchange rate constants. The curves are fitted to a quadratic equation

$$
I_{\mathrm{k} 1} / I_{\mathrm{ll}}=a \tau_{\mathrm{m}}+b \tau_{\mathrm{m}}{ }^{2}
$$

where $a=L_{\mathrm{kl}}$ and $b=1 / 2 \sum L_{\mathrm{kj}} L_{\mathrm{jl}}-L_{\mathrm{kl}} L_{\mathrm{ll}}$.

The aromatic region contains two independent exchanging spin systems, i.e., the meta protons of the A rings ( $\delta 7.0-6.35)$ and the meta protons of the $B$ (and $\left.B^{\prime}\right)$ rings $(\delta 7.45-7.1)$, which were used to obtain duplicate data. It is not necessary to determine all the matrix elements of $\mathbf{L}$, since certain pairs of $k$ 's are equal. Furthermore, in one spin system the interconversion process $P \rightleftarrows$ $\mathrm{C}$ is described by two equal pairs of cross peaks. Since we found that intensities of cross peaks, situated very close to the diagonal, are less reliable, only the well-separated cross peaks were used. Plots of $I_{\mathrm{kl}} / I_{11}$ against $\tau_{\mathrm{m}}$ were fitted with a quadratic function using the LOTUS 123 spreadsheet program. An example of a plot for the determination of $k_{\mathrm{PC}}, k_{\mathrm{CP}}$, and $k_{\mathrm{PA}}$ of compound 4 is given in Figure 3. The determination of the rate constants was carried out for calix [4]crown-2 4 at $298 \mathrm{~K}$ and for calix [4]crown-3 5 at $253 \mathrm{~K}$. The results are summarized in Table II. The rate constants follow directly from the first-order coefficients $a$ of the quadratic equation (eq 5). Since the variations in rate constants determined from 2-D spectra are related to the signal/rms noise ratio, larger errors should be found in rate constants that are

(27) Ernst, R.; Bodenhausen, G.; Wokaun, A. Principles of Nuclear Magnetic Resonance in One and Two Dimensions; the international series of monographs on chemistry; Breslow, R., Halpern, J., Rowlinson, J. S., Eds.: Oxford University Press: New York, 1987; Vol. 14.

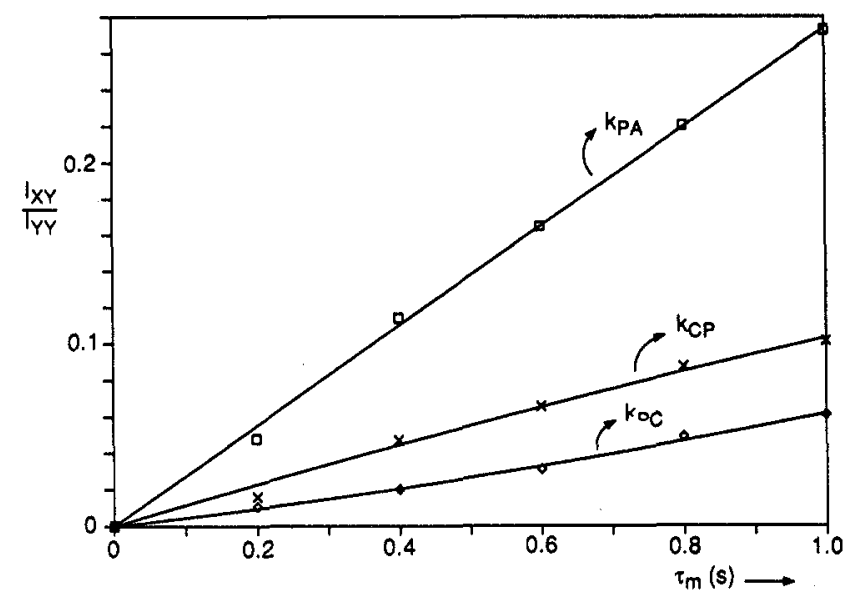

Figure 3. Plots of $I_{\mathrm{XY}} / I_{\mathrm{YY}}$ against $\tau_{\mathrm{m}}$ for the determination of $k_{\mathrm{PC}}, k_{\mathrm{CP}}$, and $k_{\mathrm{PA}}$ of calix [4]crown-2 4 .

derived from weak signals. The ratio $k_{\mathrm{CP}} / k_{\mathrm{PC}}$ is equal to the equilibrium constant $K$ for the equilibrium $\mathrm{C} \rightleftarrows \mathrm{P}$ and could also be determined independently from the ratio of conformations in the 1-D 'H NMR spectrum (Table I). Both experimental values are in good agreement with each other for compounds 4 and 5.

The rate constants $k_{\mathrm{ij}}$ obtained from the different fits were used to calculate the quadratic coefficients $b$ (eq 5), which describe two-step exchange processes. ${ }^{27}$ This provides a check on the internal consistency. The calculated and experimental values are in reasonable agreement, indicating that the experimental set of $k$ values correctly describes the total exchange process. Only for $k_{\mathrm{PC}}$ (for both compounds 4 and 5) does indirect exchange play a role within the range of $\tau_{m}$ values used. For example, the quadratic coefficient $b$ of $k_{\mathrm{PC}}$ for calix [4]crown-2 4 is $0.012 \pm$ $0.009 \mathrm{~s}^{-2}$ (calculated from the first order rate constants: 0.010 $\left.\pm 0.006 \mathrm{~s}^{-2}\right)$, which means that at the longest mixing time $\left(\tau_{\mathrm{m}}\right.$ $=1 \mathrm{~s})$ the indirect exchange process contributes up to $20 \%$. For the other processes indirect exchange processes do not significantly contribute.

The EXSY NMR experiments show that in solution the upper rim calixcrowns consist of a mixture of all the three possible conformations $\mathrm{P}, \mathrm{C}$, and $\mathrm{A}$. It should be stressed that EXSY NMR spectroscopy proves to be a very sensitive technique, because it can trace high-energy short-lived intermediates, which cannot be detected by 1-D 'H NMR spectroscopy. The partial cone $P$ is thermodynamically the most stable conformation, while A has the highest energy. For compound 4 the intensities of the cross peaks between $\mathrm{P}$ and $\mathrm{A}$ reach already at short mixing times a stationary value of $1.7 \pm 0.4 \%$ of the diagonal intensity of $P$. This reflects, as can be easily derived, the population differences of the conformations and leads to an estimate of the energy difference between $P$ and $A$ of $2.4 \pm 0.2 \mathrm{kcal} \mathrm{mol}^{-1}$. The energy differences between $P$ and $C$ are very small (e.g., $\sim 0.8 \mathrm{kcal} \mathrm{mol}^{-1}$ for compound 4). We recently calculated energy differences between conformations of nonbridged tetramethoxycalix [4]arenes by molecular mechanics in the range of 2-6 kcal mol ${ }^{-1} .^{12}$ However, these calculations were performed on isolated molecules in the gas phase.

From the dynamic NMR studies we can conclude that upper rim calixcrowns are flexible molecules, in which conformational interconversion occurs via two pathways (Figure 4). ${ }^{28}$ Starting from $P$ either the $B^{\prime}$ ring can rotate to give $C$, or the $B$ ring can rotate to give $A$. Starting from $A$ or $C$ the only possibility is to go to $P$. The determination of the rate constants of interconversion gives the striking result that both for calix[4]crown-2 4 and calix [4]crown-3 5 the process via $A$ is much faster than the process via $C$. Therefore, we can conclude that $C$ is not only thermodynamically but also kinetically more stable than $\mathrm{A}$.

For the calix[4]crowns 5-8, with bridge lengths of 9 to 18 atoms, the rate of interconversion does not change significantly, according to the similarity of the ${ }^{1} \mathrm{H}$ NMR spectra at different temperatures. However, in going from a nine-atom bridge in 5 


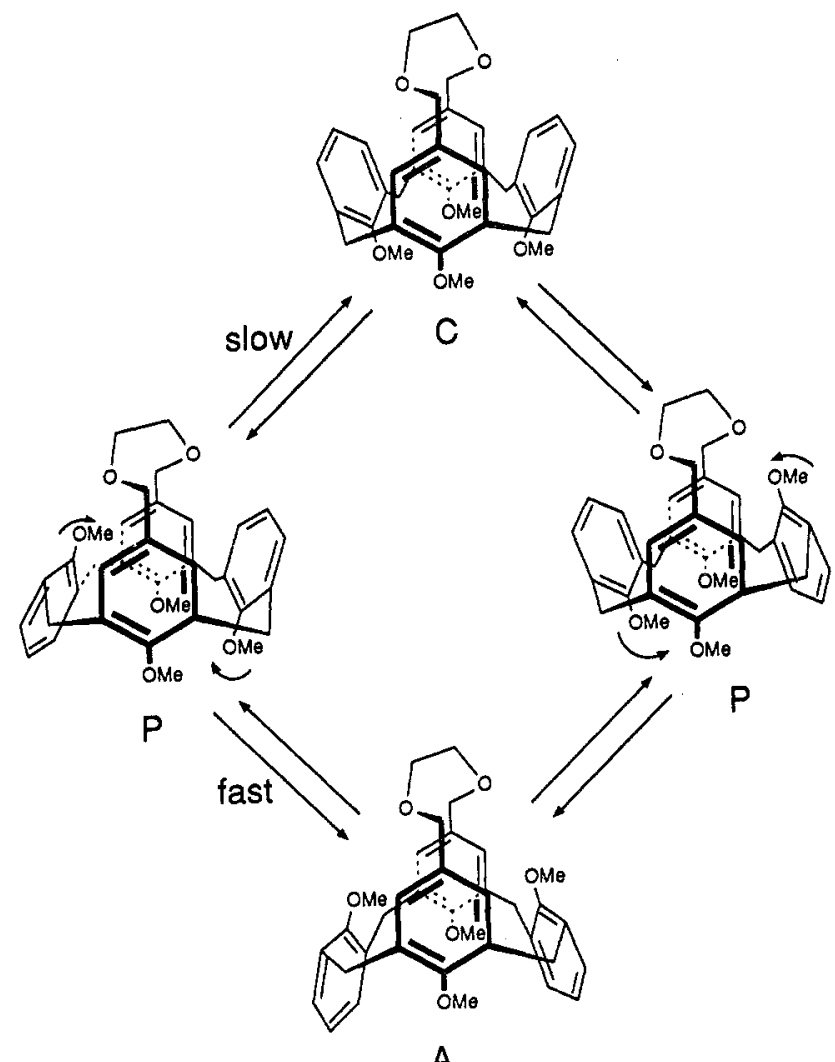

A

Figure 4. Mechanism of conformational interconversion of calix [4]crown-2 4 .

to a six-atom bridge in 4 the overall rate diminishes substantially. Since the 2-D EXSY NMR experiments for both compounds were performed at different temperatures, it is not possible to compare directly the absolute rate constants. However, the rate constant for the fast process $\left(k_{P A}\right)$ of compound 5 is already a factor of 10 higher than that of $\mathbf{4}$, although the former was determined at a $45^{\circ}$ lower temperature. This large difference in the overall rate can be explained by the fact that the six-atom bridge of 4 squeezes the two connected anisole rings together, which makes it more difficult for a methoxy group to swing through the calixarene annulus. Apparently, larger bridges hardly have an additional effect on the flexibility of the calixarene moiety. Finally, from the relative differences in the rate constants of both compounds 4 and 5 (Table II), we can conclude that shortening of the bridge has a much larger decelerating effect on the $P \rightarrow A$ pathway than on the $\mathrm{P} \rightarrow \mathrm{C}$ pathway.

In conclusion we state that the present study for the first time gives a clear insight into the conformational interconversions of calixarenes. The present study has also important implications for the nonbridged tetramethoxycalix [4]arenes, which in principle have no conformational restrictions. An investigation of p-tert- butyltetramethoxycalix [4]arene is presented in the following paper in this issue. ${ }^{29}$

\section{Experimental Section}

General Procedure for the Preparation of Upper Rim Calixcrowns 4-8. A mixture of 5,17-bis(chloromethyl)-25,26,27,28-tetramethoxycalix [4]arene $(3)^{5}(0.65 \mathrm{~g}, 1.13 \mathrm{mmol})$ and a polyethylene glycol $(1.24 \mathrm{mmol}$, 1.1 equiv) in THF $(50 \mathrm{~mL})$ was added in $24 \mathrm{~h}$ to refluxing THF ( 300 $\mathrm{mL}$ ), containing $\mathrm{NaH}$ ( $80 \%$ in oil, washed with hexane, $0.20 \mathrm{~g}, 6.8 \mathrm{mmol}$, 6 equiv), and $\mathrm{NaI}$ (spatula tip). Excess $\mathrm{NaH}$ was destroyed with a saturated $\mathrm{NH}_{4} \mathrm{Cl}$ solution. After evaporation of the solvent, the mixture was taken up in $\mathrm{CHCl}_{3}(50 \mathrm{~mL})$, and the solution was washed with brine $(25 \mathrm{~mL})$. The organic layer was dried with $\mathrm{MgSO}_{4}$ and evaporated to yield an oil, which was further purified by column chromatography in the cases of 4, 6, 7 and $8\left(\mathrm{SiO}_{2}, \mathrm{EtOAc} / \mathrm{CHCl}_{3} 3: 7\right)$. All products were obtained as oils: yields $72 \%(4), 95 \%(5), 13 \%(6),{ }^{30} 11 \%(7),{ }^{30} 39 \%$ (8). ${ }^{30}$ Spectroscopic data: see Table I.

2-D NMR Experiments. All the proton 2-D EXSY spectra were acquired at $500 \mathrm{MHz}$ with the standard NOESYPH pulse sequence $\left(90^{\circ}-t_{1}-90^{\circ}-\tau_{m}-90^{\circ}\right)$, supplied with the Bruker software, by using time-proportional phase incrementation (TPPI) ${ }^{31}$ to obtain pure phase line shapes. For both compounds 4 and 5 mixing times were chosen in the range $T_{1} / 5<\tau_{\mathrm{m}}<4 T_{1} / 5(200,400,600,800$, and $1000 \mathrm{~ms}$ for 4 and $70,100,150,200,250$, and $300 \mathrm{~ms}$ for 5 ). Typically $512 t_{1}$ increments were taken. Each FID of 2048 data points was the accumulation of 16 scans. Each scan was preceded by two dummy scans to establish steady state. The relaxation delays were chosen to be larger than $5 T_{1}$. A $\pi / 2$ shifted sine-bell window function was applied to both $F_{1}$ and $F_{2}$ domains. We found that this window function introduces very little line shape distortion and has the advantage of being parameterless compared with exponential and gaussian functions. After zero-filling in the $F_{1}$ dimension, the final data matrix size was $1 \mathrm{~K} \times 1 \mathrm{~K}$ of real data points with digital resolution of $3.3 \mathrm{~Hz}$ per point as the sweep width was 3356 $\mathrm{Hz}$ for compound $4(3.9 \mathrm{~Hz}$ per point and $4032 \mathrm{~Hz}$ for compound 5 ). Areas of cross peaks and diagonal peaks were measured directly from the 2-D display by selecting a voxel, surrounding a peak, and integrating over that volume.

The phase sensitive double quantum filtered COSY spectra were acquired according to Marion and Wüthrich. ${ }^{31}$

Acknowledgment. This investigation was supported by the Netherlands Foundation for Chemical Research (SON) with financial aid from the Netherlands Organization for Scientific Research (NWO). The 2-D NMR experiments were performed at the Dutch National NMR facility (Nijmegen, the Netherlands, supported by SON). We also acknowledge J. M. Visser and J. L. M. Vrielink for recording the 1-D NMR and T. W. Stevens for recording the mass spectra. We thank J. J. M. Joordens for the advice concerning the performing of the 2-D NMR experiments.

(28) While this manuscript was being prepared, Luz et al. reported that dodecamethoxyorthocyclophane, a cycloveratrylene derivative, shows a similar behavior: Maliniak, A.; Luz, Z.; Poupko, R.; Krieger, C.; Zimmermann, H. J. Am. Chem. Soc. 1990, 112, 4277-4283.

(29) Groenen, L. C.; van Loon, J.-D.; Verboom, W.; Harkema, S.; Casnati, A.; Ungaro, R.; Pochini, A.; Ugozzoli, F.; Reinhoudt, D. N., the following paper in this issue.

(30) Yield is not optimized.

(31) Marion, D.; Wüthrich, K. Biochem. Biophys. Res. Commun. 1983, 113, 967-974. 